\title{
DISTRIBUTION OF ANIMALS AND PLANTS IN AFRICA
}

A WHOLE-DAY meeting of the Linnean Society of London was held in the Society's rooms at Burlington House on January 29. The subject for discussion was "Problems of Distribution of Animals and Plants in Africa". In opening the meeting, the president of the Society, Lieut.-Colonel R. B. Seymour Sewell, stressed the importance of a sound taxonomic background to studies on distribution. Only when one knew with what species ono was dealing was it possible to answer questions regarding its place of origin, method of spread and eventual isolation. Other studies of importance to the biogeographer were palæontology and climatology, including the study of past climates.

The first paper was read by Mr. E. Milne-Redhead, of the Royal Botanic Gardens, Kew, who dealt with the distributional ranges of flowering plants in tropical Africa. Of the three arid regions, the Sudanese is by far the poorest and the south-western the richost floristically. The northern savannas exhibit drier (Sudanese) and wetter (Guinean) zones characterized by the presence, in the former, of numerous species of Acacia and, in the latter, of Isoberlinia. Brachystegia, which is abundant in the wetter part of the southern savanna, is absent from the corresponding zone of the northern. An additional feature of the southern savannas is the presence of $\mathbf{a}_{\mathbf{b}}$ thicket vegetation in the dry areas of central Tanganyika. The Kakamega forest marks the extreme eastern limit of the Congo forest, which was at one time much more extensive in Uganda than it is to-day. The vegetation of Uganda is now Iargely secondary and very difficult to classify. The existence of a complete gap in the dry area of the Gold Coast and Togoland is to be noted, as is the constriction of the Congo forest in the neighbourhood of the 15th meridian, which may mark the site of a former route for migration between the northern and southern savannas. The extension of forest into the savannas in the form of fringing forests along the rivers should also be noted. The small relict areas of lowland forest along the east coast are floristically different from the Guinean and Congo forests. Mr. Milne-Redhead concluded by describing distributions of individual species illustrating points of special interest. $\mathrm{He}$ ended with an appeal to zoologists to restrict the term 'Ethiopian' to the territory formerly known as Abyssinia instead of applying it, as now, to tropical Africa as a whole.

Mr. R. E. Moreau, of the Edward Grey Institute, Oxford, followed with a paper on the distribution of African evergreen-forest birds. He began by stating that, contrary to general belief, birds aro excellent zoogeographical material. Those of tropical Africa are very strictly confined to their habitats, so much so that where the latter form isolated ecological islands the avifauna frequently shows a high degree of subspecificity, an indication of the thorough reproductive isolation of populations even when these are in close gongraphical propinquity. Over most of tropical Africa the 5,000-ft. contour forms the lower limit of the montane forest birds; but in certain areas, as in the mountains near the Indian Ocean, the transition takes place at altitudes as low as $3,000 \mathrm{ft}$. Broadly speaking, it may bo said to take place between the annual isotherms of $18^{\circ} \mathrm{C}$. and $21^{\circ} \mathrm{C}$. Owing to the present very great restriction of most of the African montane forests and their isolation from the lowland forests, due partly to a dry climatic cycle and partly to human exploitation, it can only be studied in unbroken series in some areas of the eastern Belgian Congo and, on a smaller scale, on hills near the Indian Ocean. It is a remarkable fact that even in such areas as these the avifauna of the montane forest is almost as different from that of the lowland forest as it is from that of the savanna. Despite this, however, many montane species have a wide distribution in isolated forests. (An extreme example is afforded by the resemblance of the Cameroon Mountain avifauna to that of East Africa.) As against this the Abyssinian mountain fauna is much poorer than might be expected, while the degree of subspeciation even on closely adjacent mountains in East Africa is high. In conclusion, Mr. Moreau suggosted some possible features of the climatic history of the continent which might help to account for these facts. Viewed in toto, however, the problem of the origins of the present distribution of forest birds remains a most baffling one.

The last paper of the morning session was read by Dr. A. T. Hopwood, of the British Museum (Natural History), on the origin and history of the African mammalian fauna. He began by stressing the difficulty of dating the available fossil remains. This arises mainly from two causes, the virtual absence of marine deposits and the difficulty of distinguishing ccological differences from differences of age. Like the birds, the mammals tend to be closely restricted to their preferred habitats, and in consequence distinct savanna and forest forms may be found in close geographical proximity. Oligocene deposits are rich in Hyracoidea and Proboscidea, both of which are probably African in origin, although the Oligocene Proboscidea of Baluchistan have some very primitive features. The Oligocene of the Fayum and of Baluchistan is also very rich in anthracotheres. Large collections are available from the Lower Miocene of Central Africa. These have not yet been fully worked out; but the fauna is known to have contained primitive mastodons, very close to those of the Upper Oligocene of Baluchistan, well-developed chrysochlorids (an apparently autochthonous group) and many rodents and creodonts as well as the earliest known fossil aardvark. 'The latter may possibly have been a Lower Miocone or Oligocene invader. The Miocene fauna of Kenya shows a close resemblance to that of south-west Africa, except that the latter contains no primates. No Pliocene remains are yet known. The Pleistocene fauna shows a very close resemblance to that of the recent era, many forms being scarcely even specifically distinct. Hippopotamus and giraffe first appear in Africa in the Lower Pleistocene and were almost certainly invaders from Asia, perhaps from India.

In the afternoon the chair was taken by Dr. W. E. Swinton. Mr. P. F. Mattingly, of the British Museum (Natural History), opened the session with a paper on the distribution of African mosquitoes. He began by discussing the elimatic limits of Chapin's faunal districts, speaking mainly with reference to the subgenus Stegomyia. Only two species of this subgenus are naturally distributed throughout the Upper and Lowor Guinean Forest districts, an example of the exclusive nature of the evergreen forest. Both species 
extend into the surrounding savannas. Wo the north they are limited by the 40-in. isohyet which here seems to form the natural boundary of the West African subregion. To the east they extend into the Kakamega forest, and the limit here seems to be an altitudinal one, about $5,500 \mathrm{ft}$. in the case of one species and about $6,000 \mathrm{ft}$. in the case of the other. To the south this difference allows one species to spread up on to the Rhodesian plateau, while arresting the other at about $3,500 \mathrm{ft}$. and confining it to the western subregion. Evidence was brought to show that the effect of rainfall on distribution may be largely indirect, the operative factor being the subsoil waterlevel which determines the nature of the vegetation, and so of the microclimate. The existence of a West African savanna species with a discontinuous distribution in the coastal area of Natal and Zululand indicates a former much wider extension of the central African forests. The affinities and distribution of the East African Highland fauna were discussed, and attention was directed to the existence of a typical member of the African group of Stegomyia in a restricted area of eastern Asia. This was discussed in relation to the origins of the African fauna, and notes were given on geographical variation and the zoogeography of introduced species.

Prof. P. C. C. Garnham, of the London School of Hygiene and Tropical Medicine, then read a paper on the distribution of blood protozoa in Africa. He said that, with the exception of a few groups of special importance, this was practically a virgin field. In addition to the two factors discussed by previous speakers, the organism and its environment, it was necessary to take account of two more, the host and the vector. There could be no zoogeography of the blood protozoa per se but for the fact that there occur cases in which the host and the vector are present but the parasite is not. The factor of human interference was of special importance because man could act separately on parasite, host or vector, exterminating or reducing them or increasing their numbers by importation, domestication or transportation to more suitable environments. The best parasites to study would be those whose hosts are static or have a limited range. Unfortunately, data concerning these are scanty. Examples were then given from the malaria parasites, of which the human forms occur throughout Africa, except in deserts and above certain altitudes (about 9,000 ft. in equatorial latitudes), the related Hæmoproteidæ, the hæmogregarines, the trypanosomes and the piroplasms, all of which show interesting examples of discontinuous or restricted distributions.

Dr. W. E. Kershaw, of the Liverpool School of Tropical Medicine, followed with a short paper on the distribution of human filarial parasites in West Africa. He said that the distribution of these parasites could be related in varying degrees to the vegetational zones, though less clearly than in free-living animals. The human parasite Loa loa occurs, it is believed, also in monkeys. It is transmitted by biting flies (Chrysops), which feed on monkeys in the canopy and on man either on the ground or in houses built on ridges level with the canopy. The parasite is confined to the evergreen forest and disappears as soon as the forest fringe is crossed. Acanthocheilonema perstans is also ubiquitous in the forest and absent from the mountain grassland, despite the presence there of one of its vectors (Culicoides spp.). It is also abundant, however, in the arid, eroded grasslands of the Bauchi plateau. It seems, therefore, that, in this case, very different vegetational zones can provide suitable conditions for the maintenance of the parasite.

This session concluded with a paper by Dr. E. B. Worthington, of the Conseil Scientifique pour l'Afrique au Sud du Sahara, on the distribution of freshwater organisms. He said that the continent could be divided into ten aquatic regions, but confined his remarks mainly to the eastern and central area comprising six regions, the Nilotic, Victorian, Tanganyikan, Nyasan, Zambesian and East Riverain, pointing out that these were not all coincident with drainage basins because in some cases differences in ecological conditions formed more potent barriers than dry land. Small freshwater organisms and even fish may become airborne at times. Discussing the mode of origin of present-day distributions, he suggested a hypothesis, based on past tectonic and climatic changes, to account for the picture now presented by the great lakes of East Africa. This hypothesis, he said, had first been put forward twenty years ago, but it had stood the test of time and still seemed worth restating. Active work was in progress and details were continually being filled in. Finally, he directed attention to the great interest of studies on such phenomena as the Haplochromis species swarms of Lake Victoria for general evolutionary theory and for our understanding of the mechanism of speciation. $\mathrm{H}_{\theta}$ said that, despite criticism, he still adhered to his opinion regarding the importance, in this connexion, of the absence of predators. He concluded by referring to the, factor of human interference. This had a long history but had recently been intensified by such developments as fish farming and the use of fish in the control of disease. In some cases it was irretrievably altering local conditions before sufficient had been learnt about them.

The whole of the evening session was devoted to an open discussion. Contributions of the principal speakers will be published in full, with a report on the discussion, in the Proceedings of the Linnean Society.

P. F. Mattingliy

\section{THE BIRTH OF FLIGHT* \\ By the Right HON. LORD BRABAZON OF TARA, P.C.}

A LTHOUGH from earliest times smoke must have been noticed to arise from fire, it was not until the eighteenth century that the brothers Montgolfier realized the principle of using hot air to make $\mathbf{a}_{\mathrm{b}}$ balloon rise. Yet such a primitive people as the Australian aborigines invented the boomerang, which aerodynamically shows three remarkable characteristics : the lift obtained from a surface which is flat on the underneath but curved on the top; the recession of the axis of rotation due to a force on one side of the rotating body; and the auto-rotating effect of a boomerang due to the change of kinetic energy into rotational enorgy (at the end of its flight the boomerang rotates more violently than when launched).

Nature provides a varied selection of methods of flight. Thus there are the gliding seeds, of which a number among the conifers give remarkably long glides, and auto-gyration in Nature is illustrated by

* Substance of a Friday Evening Discourse delivered at the Royal Institution on February 20. 